Tersedia online di http://ejournal.undip.ac.id/index.php/kiryoku

\title{
PENDIDIKAN ANAK MODEL ORANG TUA DI JEPANG
}

\author{
Iriyanto Widisuseno \\ Fakultas Ilmu Budaya Universitas Diponegoro \\ widisusenoiriyanto@yahoo.co.id
}

\begin{abstract}
s
(Title: Home Education By Parents In Japan) Each nation has its own educational pattern, according to its cultural values. To see the character of a banga need to examine how the education of children based on the cultural values it embraces. Japan is known as a nation whose nation is disciplined, hardworking, and independent. This kind of Japanese character can be formed through the ways parents in Japan in educating their children in the family environment. This study would like to reveal the pattern or way parents in Japan in educating their children. The length of this study is important when looking at the fact that the Japanese state to date has become a developed country and has strong economic stability and security. The role of the characters that shape the mental attitude of the Japanese becomes an important factor. The position and function of the family in the education of Japanese character as the leading sector. Parents as role models for children at home, namely in the introduction and planting value of empathy, discipline, ethics and Gambaru.
\end{abstract}

Keywords: children's education, family, parents, character

\section{PENDAHULUAN}

Jepang terkenal sebagai negara yang masyarakat bangsanya disiplin, pekerja keras, dan mandiri. Di bidang ekonomi Jepang telah mencapai tingkat perekonomian tertinggi di Asia Timur. Sementara jumlah penduduk Jepang hanya 127 juta jiwa dan luas wilayahnya $377,962 \mathrm{~km}^{2}$, jauh lebih kecil dibandingkan dengan Indonesia dengan jumlah penduduk 250 juta jiwa dan luas wilayah negara 1.905 million $\mathrm{km}^{2}$. Faktanya sekarang negara Jepang mampu menguasai pasar industri di dunia, termasuk di Indonesia.

Bangsa Jepang bisa sukses bukan tanpa tantangan, sejarah memperlihatkan banyak sekali tantangan yang selama ini berhasil dilalui oleh masyarakat Jepang. Ketangguhan bangsa Jepang telah teruji, misalnya ketika dalam perang Dunia II, kota Nagasaki dan Hiroshima hancur di bom Atom oleh tentara Sekutu. Semua sarana infrastruktur negara Jepang hancur, Kaisar Hirohito langsung menanyakan kepada rakyatnya: masih berapa jumlah gurunya?. Sikap elegan yang luar biasa dimiliki oleh Kaisar waktu itu ialah para guru Jepang yang tersisa segera disekolahkan di Amerika. Sikap mental Kaisar untuk atas nama bangsa Jepang memiliki jiwa sportif dan elegan, yaitu mengakui bahwa Amerika adalah negara yang kuat dan perlu belajar dari ilmunya agar kelak dikemudian hari bangsa Jepang bisa mengalahkannya. Bukti lain saat peristiwa Tsunami di tahun 2011 silam, meskipun dalam kondisi tertimpa musibah, kelaparan dan berbagai kesulitan, tidak terjadi sebuah tindakan seperti penjarahan atau saling berebutan makanan. Para korban tetap mengantri dengan rapi ketika mendapat bantuan, dan tidak terlihat sebuah sikap meratapi nasib atau iba meminta bantuan. Mereka tetap sabar, dan tenggang 
rasa. ketika ditimpa bencana mereka tetap berjuang. Ketangguhan sikap mental seperti ini adalah wujud slogan dari "Ganbaru”yang selalu diserukan oleh mereka (Asep Firmansyah: https://japanesian.id/tips-mendidik-anak).

Kemajuan negara Jepang tentu tidak terlepas dari peran sistem pendidikan negara yang sangat baik, yakni system pendidikan yang dikonstruksikan oleh peran pendidikan keluarga.

Permasalahannya, bagaimana masyarakat Jepang mengkonsepsikan keluarga sebagai bagaian inti institusi pendidikan. Bagaimana posisi dan peran keluarga dalam pendidikan anak usia dini. Bagaimana model orang tua dalam mendidik anak di lingkungan keluarganya. Bagi negara Jepang, keluarga adalah leading sector bagi pendidikan dan orang tua merupakan role model dalam pendidikan keluarga. Meskipun Jepang telah menjadi negara maju dibidang teknologi, namun kepatuhan masyarakat Jepang terhadap nilai-nilai tradisi leluhur, moral dan etika tidak luntur. Dalam pendidikan di Jepang terdapat model khas orang tua dalam mendidik anak-anaknya hingga terbentuk generasi bangsa yang tangguh dan berkarakter. Kajian ini tentu tidak mengasumsikan bahwa pendidikan anak di Jepang baik segalanya, oleh karena itu peneliti secara eklektik memilah-milah dan menyeleksi model-model orang tua di Jepang dalam mendidik anak di lingkungan keluarganya.

\section{METODE PENELITIAN}

Penelitian ini menggunakan studi literature dan bersifat kasuistis. Tergolong lingkup kajian antropologi budaya, dengan objek materialnya masyarakat bangsa Jepang dan fokus kajiannya (objek formal) yaitu cara orang tua masyarakat Jepang dalam mendidik anak dalam keluarga. Untuk mengungkap dan menemukan polapola perilaku orang tua di Jepang dalam mendidik anak, peneliti menggunakan pendekatan historis factual, dan metode deskripsi kualitatif. Pendekatan historis factual mengarahkan peneliti pada unsurunsur perilaku simbolik atau pola perilaku orang tua dalam masyarakat Jepang yang dipraktikkan secara menggenerasi dan sistematis sebagai fakta sejarah memiliki nilai edukatif membentuk sikap mental dan kepribadian masyarakat Jepang. Metode deskripsi kualitatif, mengekplorasi arti dan makna edukatif yang terdapat dalam data sebagai gambaran perilaku orang tua dalam mendidik anak. Metode analisis deskriptif ini mencoba mengeksplorasi struktur budaya Jepang berupa pola perilaku orang tua dalam mendidik anak, kemudian secara eklektik memilahkan, dan menyaring dalam strukur dan mengkomprehensikan kesatuan sistematis yang bermakna.

\section{PEMBAHASAN}

Konsep dan Struktur Keluarga di
Jepang

Konsep keluarga di Jepang pada prinsipnya tidak berbeda dengan konsep keluarga pada umumnya di negara lain termasuk Indonesia. Keluarga adalah kelompok sosial yang terdiri dari kerabat dekat, orang tua-anak dan pasangan suami istri yang menjalani kehidupan bersama sehari-hari. Tujuan dibentuknya keluarga adalah untuk memperoleh kesejahteraan yang dilandasi adanya ikatan hubungan suami dan istri yang terdiri dari orang terdekat dalam jumlah kecil seperti ayah, ibu, dan anak-anak. Menurut Friedman (1998), keluarga adalah dua atau lebih individu yang tergabung karena ikatan tertentu untuk saling membagi pengalaman dan melakukan pendekatan emosional, serta mengidentifikasi diri $\mathrm{m}$ ereka sebagai bagian dari keluarga. Keluarga merupakan unsur inti masyarakat yang saling megikatkan diri kedalam satu ikatan kultural, ideologis dan geografis 
menjadi sebuah komunitas besar dan terorganissi yang disebut bangsa.

Sistem keluarga dalam masyarakat Jepang pada masa sebelum perang Dunia ke II hidup dalam bentuk keluarga besar (extended family) dengan sistem pranata tradisional (ie), yaitu menekankan pada pemujaan arwah leluhur, mempertahankan eksistensi keturunan langsung dari generasi ke generasi yang dianggap penting untuk kehidupan bersama. Struktur keluarga besar mencakup keluarga inti ditambah anggota keluarga lain yang masih mempunyai hubungan darah, seperti kakek, nenek, paman, dan bibi. Bentuk keluarga besar tersebut saat ini mengalami penurunan dikarenakan industrialisasi yang terjadi di Jepang. Sekarang sebagian besar masyarakat Jepang, hidup dalam keluarga inti atau nuclear family. Struktur keluarga inti terdiri dari ayah, ibu dan anak yang diperoleh dari keturunannya atau adopsi atau keduanya.

\section{Posisi Keluarga dan Peran Orang Tua dalam Pendidikan Anak di Jepang}

Posisi keluarga di Jepang merupakan bagian penting dari pilar pendidikan. Tiga pilar penting dalam dunia pendidikan, yakni keluarga, satuan pendidikan, dan lingkungan masyarakat. Ketiga pilar dalam pendidikan itu harus saling mendukung dalam membangun karakter yang baik (Azzel 2011: 112). Di Jepang, keluarga merupakan basis dan matarantai terdepan dalam system pendidikan. Keluarga merupakan salah satu mata rantai kehidupan yang paling esensial dalam perjalanan hidup anak manusia. Sekaligus menjadi awal mula pendidikan itu dikenalkan

(Syarifuddin:

https://sulselprov.go.id/post/keluargasebagai-lingkungan-awal-pendidikan-anak). Peran orang tua sangat vital dalam pendidikan keluarga. Bangsa Jepang mempunyai dasar karakter yang kuat, dan karakter ini tidak diajarkan di sekolah. Pelajaran agama juga tidak diajarkan di Sekolah-sekolah Jepang, tetapi dibentuk sejak mereka kecil (https://anieristyan.wordpress.com/. Tradisi pendidikan anak semacam ini telah berlangsung sejak sebelum Perang Dunia ke II hingga sekarang. Yaitu ketika masyarakat Jepang masih menganut pola keluarga besar ((extended family) dengan pranata tradisional $(e)$ kebanyakan anak diasuh oleh nenek. Dahulu bagi seorang ibu, mempunyai anak sendiri berarti mempunyai persyaratan untuk mendapatkan jaminan akan tinggal di dalam keluarga suaminya (Fukutake, 1988: 54). Sekarang pola keluarga yang dianut masyarakat Jepang bergeser ke pola keluarga inti (nuclear family), anak-anak diasuh oleh orang tua (ayah dan ibu). Mekipun telah terjadi pergeseran pola keluarga di Jepang, tetapi posisi keluarga masih ditempatkan sebagai mata rantai kehidupan yang paling esensial dalam perjalanan hidup anak, dan menjadi awal mula pendidikan itu dikenalkan.

\section{Pendidikan Anak Model Orang Tua di Jepang}

Dalam pandangan filosofi bangsa Jepang, anak dimaknai sebagai aset negara. Masa depan negara di atas pundak mereka, oleh karena itu pendidikan harus diorientasikan untuk kepentingan masa depan mereka. Pendidikan keluarga (preschool) oleh para orang tua dilakukan untuk mempersiapkan dan mendampingi anak memasuki sekolah. Jepang menganut sistem pendidikan wajib belajar 9 tahun, dimulai sejak usia 6 tahun. Sistem pendidikan ini tidak jauh berbeda dengan Indonesia. Selain pendidikan wajib belajar 9 tahun, di Jepang juga telah menyiapkan pendidikan anak sejak dini. Pendidikan anak usia dini di Jepang terbagi dua yaitu Youichien (di Indonesia menyebutnya sebagai Taman Kanak-Kanak (TK)) dan Hoikuen (di Indonesia menyebutnya sebagai Taman Penitipan Anak (TPA), sementara di Amerika lebih populer dengan istilah daycare/nursery school). Tujuan utama pendidikan anak usia dini di Jepang baik Youchen (TK) ataupun Hoikuen (TPA/daycare) sama yaitu membangun 
kekuatan anak untuk hidup dan memiliki landasan hidup yang kuat untuk menapaki langkah selanjutnya. Landasan hidup beupa kesehatan fisik dan mental, hubungan sosial yang baik, hubungan yang baik dengan lingkungan, kemampuan berbahasa serta kemampuan ekspresi, kreativitas, dan seni. Sehingga pendidikan tidak hanya dari orang tua, namun juga dari sekolah dan masyarakat. Pendidikan anak usia dini di Jepang sebagai salah satu langkah penting dalam pembentukan karakter mereka (Zuhayratu Zzaffan: https://zuhayratuzzaffan.wordpress.com/20 $\underline{15 / 07 / 31 / \text { resensi-pendidikan-anak-ala- }}$ jepang/

Model orang tua di Jepang dalam mendidik anaknya selalu menasehati anaknya, perlakukan orang lain seperti kamu ingin diperlakukan. Setiap tindakan anak akan selalu membawa akibat kepada orang lain. Jadi ia akan terbiasa mementingkan perasaan dan kepentingan orang lain lain terlebih dahulu sebelum kepentingannya sendiri (Kirito: https://keepo.me/jerichoimanuel/cara-danperan-orang-tua-di-jepang-dalammendidik-anaknya-yang-berlawanandengan-di-indonesia).

Karakter terbangun dari kebijaksanaan (virtues) yang melekat pada jati diri seseorang. Sebagai bentuk dari pengungkapan nilai, maka karakter terbangun dari seperangkat nilai luhur yang dijadikan 'keyakinan utama' (level of belief) dari suatu masyarakat. Nilai-nilai itu tergali dari kebudayaan yang meliputi nilai sosial, nilai budaya, nilai ideologis, nilai agama, nilai estetis (seni). Nilai-nilai itu mengandung keutamaan tertentu (the good) yang kemudian berkembang sebagai dasar moralitas (common ground morality) sehingga karakter menjadi sebuah sistem makna yang tidak lagi berfungsi privat tetapi berfungsi publik (Budimansyah, $2010: 30-31$ ).

Tradisi di Indonesia anak-anak itu dianggap makhluk usia emas (golden age) yang tidak boleh banyak dilarang, dianggap akan menghambat perkembangan kreativitasnya. Padahal sebenarnya anak sejak usia dini harus dididik untuk memahami aturan yang ada. Seperti berikut ini pendidikan orang tua Jepang ketika terhadap anaknya agar bisa tumbuh berkembang dengan baik.

\section{a. Anak-anak diajari Berempati}

Berempati artinya memahami perasaan dan keadaan orang lain atau lingkungan. Pentingnya rasa empati bagi anak, dapat mengembangkan rasa teposaliro di tengah kehidupan sosial anak, melatih kepekaan sosial. Orang tua di Jepang selalu menasehati anaknya untuk memperlakukan orang lain seperti perlakuan terhadap diri sendiri. Sebab, setiap tindakan seseorang akan berakibat pada orang lain. Anak sejak kecil akan terbiasa mementingkan perasaan dan kepentingan orang lain terlebih dahulu sebelum mengejar kepentingannya sendiri. Anak-anak dari kecil sudah tertanam nilainilai kehidupan kolektivs, Itulah sebabnya system sosial masyarakat Jepang menganut pola kolektivisme. Menurut Chie Nakane dalam Yudhasari (2003:34), menyebut masyarakat Jepang sebagai masyarakat kelompok. Sebagai masyarakat kelompok, masyarakat Jepang terkenal sebagai masyarakat yang sangat loyal satu sama lain. Dalam suatu keluarga terjalin suatu hubungan yang sangat mendalam dan kuat. Hubungan antar anggota keluarga pada masyrakat Jepang tidak saja berlangsung selama mereka masih hidup, tetapi setelah mereka meninggal dunia pun masih memiliki keterkaitan satu dengan lainnya. Seperti yang nampak dalam upacara Obon, yaitu upacara yang digelar untuk mendoakan arwah leluhur dengan cara berziarah, adalah bukti nyata bagaimana kuatnya hubungan antaranggota keluarga (Yudhasari, 2003:3). 


\section{b. Membiasakan Disiplin}

Tradisi di Jepang, posisi ibu lebih dominan dalam mendidik anak dalam keluarga. Ibu lebih banyak menyempatkan waktunya untuk mendampingi anak sehariharinya. Tidak sedikit ibu-ibu di Jepang memilih sebagai ibu rumah tang murni di rumah, karena memilih untuk menunggui anak-anaknya di rumah atau di luar rumah. Sejak kecil anak-anak Jepang sudah diperkenalkan nilai-nilai kedisiplinan oleh orang tuanya. Misalnya, kalau di jalan tidak boleh membuang sampah di tempat sembarangan. Jika terjadi pelanggaran disiplin, orang tua tidak segan-segan menghukum anaknya, misalnya dengan cara memukul bagian tubuhnya. Namun jarang orang tua di Jepang menghardik anaknya karena melanggar disiplin di muka umum, setelah di rumah baru dilakukan. Itulah sebabnya anak-anak pada takut melanggar disiplin, selalu taat peraturan dan tatatertib kehidupan sehari-hari. Prinsip yang dianut dalam menanamkan kedisiplinan, mulai dari mengenalkan, membiasakan, akhirnya merasuk jadi karakter. Karakter anak di Jepang terbentuk mulai dari usia awal mengenali orang tuanya, terutama ibunya.

\section{c. Pengenalan Etika}

Tradisi di Jepang pengenalan etika pada anak-anak usia dini dimulai dari kehidupan di dalam keluarga, di sekolah atau pun di lingkungan masyarakat dan berjalan secara masif konsisten. Semua komponen masyarakat, baik keluarga dan sekolah, mengajarkan anak untuk beretika dan bersopan santun. Jika bermain bersama, si anak ingin meminjam mainan temannya maka harus meminta ijin terlebih dahulu. Jika diijinkan maka harus mengucapkan terima kasih. Setelah selesai bermain juga harus mengucapkan terima kasih lagi. Jika melakukan kesalahan baik di sengaja ataupun tidak, anak harus meminta maaf dan temannya harus memberikan maafnya. Anak-anak tidak boleh mengambil yang bukan miliknya. Semua harus meminta ijin terlebih dahulu (http://rahasiaibunda.blogspot.co.id/2015/1 2/metode-pendidikan-anak-di-jepangyang.html )

Bangsa Jepang mempunyai dasar karakter yang kuat. Pelajaran etika, agama tidak diajarkan di Sekolah-sekolah Jepang, tetapi dibentuk sejak mereka kecil dalam kebudayaan Samurai. Prinsip moral ini berasal dari kebudayaan Samurai yang terdiri dari 4 karakter yang disebut ON, GIMU, GIRI dan NINJO. Masyarakat Jepang mendapatkannya dari orang tua mau pun masyarakat sekitarnya.

\section{Gambaru}

d. Penanaman Nilai Falsafah

Menurut Kamus Bahasa Jepang, doko made mo nintai shite doryoku suru (bertahan sampai kemanapun juga dan berusaha habis-habisan). Gambaru sendiri terdiri dari dua karakter, yaitu karakter "keras" dan "mengencangkan". Jadi gambaran yang bisa didapat dari paduan karakter ini adalah "mau sesusah apapun itu persoalan yang dihadapi, kita mesti keras dan terus mengencangkan diri sendiri agar kita bisa menang atas persoalan itu" Gambaru bukan hanya sekadar berjuang tanpa spirit lalu kalau ada banyak rintangan, berhenti saja. (https://terlaloo.blogspot.co.id/2015/12/ga mbaru-falsafah-hidup-bangsa-jepang.html)

Sejak anak usia dini sikap Gambaru sudah ditanamkan, baik melalui pendidikan keluarga oleh orang tua di rumah maupun ketika anak-anak di sekolah. Misalnya, anak-anak dilarang memakai sandal di rumah, agar telapak kaki dapat menyentuh lantai, lebih mengutamakan cara berjalan kaki ketika bepergian, memakai baju yang tipis di musim dingin agar tidak terbiasa manja, jika hanya sedikit sakit ringan anak diajari tidak perlu membolos sekolah, tetap masuk dari pagi hingga sore, dengan alasan 
anak akan kuat menghadapi masalah jika ia melawan masalahnya.sendiri.

Peranan Gambaru dalam membentuk sikap hidup orang Jepang sangat penting. Contoh nyata dapat kita lihat setelah terjadi tsunami dan gempa bumi berkekuatan 9.0 SR di Jepang bagian timur. Ini merupakan tsunami dan gempa bumi terbesar di dunia. Sangatlah wajar jika pemerintah dan warga Jepang akan panik dan kebingungan karena bencana ini. Wajar pula jika melihat banyak warga menangis dan stasiun televisi mulai menayangkan potret korban yang diiringi latar lagu melankolis yang menyedihkan. Namun, apa yang terjadi pasca bencana mengerikan tersebut? Unsur-unsur di atas sama sekali tidak disiarkan di TV, yang malah disiarkan adalah peringatan pemerintah agar setiap warga waspada, himbauan pemerintah agar seluruh warga Jepang bahu-membahu menghadapi bencana, permintaan maaf pemerintah karena terpaksa melakukan pemadaman listrik, potret warga dan pemerintah yang bahu-membahu menyelamatkan warga lainnya, dan tips-tips menghadapi bencana alam (https://terlaloo.blogspot.co.id/2015/12/ga mbaru-falsafah-hidup-bangsa-jepang.html)

\section{SIMPULAN}

Mewujudkan tujuan pendidikan bukan monopoli tanggungjawab pemerintah, tetapi tanggungjawab bersama pemerintah, keluarga dan masyarakat. Proses pendidikan tidak mungkin berjalan dengan baik dan berhasil optimal apabila hanya satu pihak yang berperan, tanpa keterlibatan pihak lain di dalamnya. Menurut pendapat Sukmadinata (2004, hal 233), bahwa interaksi pendidikan dapat berlangsung dalam lingkungan keluarga, sekolah, masyarakat, serta lingkungan kerja, maka keberhasilan penyelenggaraan pendidikan karakter akan sangat dipengaruhi oleh faktor-faktor tersebut, karena saling berkaitan satu dengan yang lainnya, masing-masing saling mempengaruhi. Itulah sebabnya Azzel (2011, hlm. 112) mengatakan bahwa tiga pilar penting dalam dunia pendidikan, yakni keluarga, satuan pendidikan, dan lingkungan masyarakat.
Jadi, ketiga pilar dalam pendidikan itu harus saling mendukung dalam membangun karakter yang baik.

Ketiga pilar pendidikan tersebut, di Jepang berjalan secara sistemik. Keluarga merupakan pilar terdepan pendidikan. Keluarga yang baik adalah awal dari masyarakat yang sejahtera. Sebaliknya, keluarga yang amburadul adalah pertanda hancurnya sebuah masyarakat. Individuindividu yang baik akan membentuk keluarga yang harmonis. Keluarga-keluarga yang harmonis akan mewujudkan masyarakat yang aman dan damai. Selanjutnya masyarakat-masyarakat yang damai akan mengantarkan pada negara yang kokoh dan sejahtera. Apabila ingin mewujudkan negara yang kokoh dan sejahtera bangunlah masyarakat yang damai. Apabila ingin menciptakan masyarakat yang damai binalah keluarga-keluarga dengan baik dan harmonis (Hidayatullah, 1994, hlm. 2).

Konsep tersebut dipraktikan di negara Jepang. Posisi keluarga menjadi leading sector dalam proses pendidikan. Oleh karena itu sebagai orang tua harus sangat hati-hati dalam mendidik anak, karena hasilnya akan sangat berpengaruh terhadap kepribadian dan juga kebiasaan anak di masa yang akan datang

\section{DAFTAR PUSTAKA}

\section{Azzel. 2011. Urgensi Pendidikan Karakter} di Indonesia : Revitalisasi Pendidikan Karakter terhadap Keberhasilan Belajar dan Kemajuan Bangsa. Yogyakarta, Ar - Ruzz Media.

Budimansyah, Dasim. (ed). 2012. Perancangan Pembelajaran Berbasis Karakter Seri Pembinaan Profesionalisme Guru. Bandung, Widya Aksara Press. 
Kiryoku, Volume 2 No 1, 2018

e-ISSN:2581-0960, p-ISSN: 2599-0497

Tersedia online di http://ejournal.undip.ac.id/index.php/kiryoku

Hidayatullah F.2010. Pendidikan Karakter Membangun Peradaban Bangsa. Surakarta, Yuma Pustaka.

Sukmadinata. 2004. Landasan Psikologi Proses Pendidikan. Bandung, Remaja Kosdakarya.

\section{DAFTAR LAMAN}

Asep Firmansyah: https://japanesian.id/tipsmendidik-anak

Kirito:

https://keepo.me/jerichoimanuel/cara -dan-peran-orang-tua-di-jepangdalam-mendidikanaknya-yangberlawanan-dengan-di-indonesia
Syarifuddin:

https://sulselprov.go.id/post/keluarga -sebagai-lingkungan-awalpendidikan-anak

https://anieristyan.wordpress.com/.

http://rahasiaibunda.blogspot.co.id/2015/12 /metode-pendidikan-anak-di-jepangyang.html

https://terlaloo.blogspot.co.id/2015/12/gam baru-falsafah-hidup-bangsajepang.html 